\title{
Comparative Study between the Effect of Nifedipine, Ritodrine and Magnesium Sulphate Therapy on Doppler Indices of Fetal Umbilical and Middle Cerebral Arteries in Patients with Preterm Labour
}

\author{
Hosam Eldin Hussein Kamel*, Noha Mohamed Sabri HosamEldin*, Mohamed Ahmed Attia Soltan * \\ *Department of Obstetrics and Gynecology Department, Faculty of Medicine, Al Azhar University
}

Corresponding author: Mohamed Ahmed Attia Soltan, Mobile: 00201021543881, E-Mail: mhmd.soltan2917@gmail.com

\begin{abstract}
Background: Spontaneous preterm labor (SPTL) and preterm birth (PTB), is the single most important cause of perinatal mortality and morbidity in high-income countries despite the enormous efforts over the past several decades. Preterm labor is defined as regular, painful, frequent uterine contractions causing a progressive effacement and dilatation of the cervix occurring before 37 completed weeks of gestation. Many drug therapies were used as tocolytics in cases of preterm labor, however none of them proved to be the best. The present study was performed to compare three of the used drugs for tocolysis to assess their efficacy and side effects on the mother and fetus.

Aim: The aim of this study is to compare the effect of oral nifedipine, intravenous ritodrine infusion and magnesium sulfate infusion used as tocolytics in cases of preterm labour on Doppler parameters of fetal umbilical and middle cerebral artery and to evaluate their effects on the mother and the fetus in order to choose the safest and the most effective drug.

Methodology: This study was held in the period from December 2014 to october 2015 on 90 patients attended and admitted from the Casualty Unit of the Obstetric Department In Elsayed Glal University Hospital with preterm labor pains, intact membranes, singleton pregnancy between 28 and completed 34 weeks gestation. All patients had been dated accurately with a gestational age based on the last menstrual period and if available a corresponding second trimester ultrasound report performed before 20 weeks gestation.

Treatment continued until contractions stopped for 24 hours, maximum doses were attained without response; unacceptable side effects occurred or labor proceeded. Successful treatment was defined as cessation of contractions observed for 24 hours and no further cervical changes. Patients with successful treatment were put under observation for another 24 hours without additional treatment then discharged on no maintenance therapy.

Results: Maternal tachycardia, palpitation and dyspnea were more common in the ritodrine group with (pvalue $=0.000$ ). The present study showed increase in umbilical artery PI after treatment in the magnesium sulfate group only which was statistically significant $(\mathrm{P}$ value $=0.016)$. The study showed statistically significant increase in middle cerebral artery PI after treatment in magnesium sulfate group with a P value $=0.000$ and statistically significant decrease in middle cerebral artery with nifedipine group with $P$ value $=0.027$. When comparing the cerebroplacental ratio before and after treatment in the three groups; the study showed significant increase in cerebroplacental ratio after treatment in the magnesium sulfate group with $\mathrm{P}$ value $=0.000$, which is statistically significant. This suggests that nifedipine could be used as a safer alternative to ritodrine and magnesium sulfate.

Conclusion: In our study, nifedipine therapy was not associated with a significant change in maternal systolic and diastolic blood pressure after $24 \mathrm{~h}$, with minor insignificant effect on maternal heart rate. Fetal heart rate was not affected after therapy. Fetal Doppler study found no clinically significant effect on the pulsatility index (PI) of umbilical and middle cerebral artery, while with magnesium sulfate therapy there was increase in cerebro- placental ratio $24 \mathrm{hr}$ after treatment, these findings ensure safety of the drugs on the maternal and fetal aspects.
\end{abstract}

Keywords: Nifedipine, Ritodrine, Magnesium Sulphate, Fetal Umbilical, Preterm Labour

\section{Introduction}

Preterm labor is defined as the presence of uterine contractions of sufficient frequency and intensity to affect progressive effacement and dilation of the cervix prior to term gestation (between 20 and $37 \mathrm{wk}$ ). Preterm labor precedes almost half of preterm births and preterm birth neonatal mortality in the United States. In addition, preterm birth accounts for $70 \%$ of neonatal 
morbidity, mortality, and health care dollars spent on the neonate, largely due to the $2 \%$ of American women delivering very premature infants $(<32$ wk) ${ }^{(1)}$.

The exact mechanism(s) of preterm labor is largely unknown. However, it is believed to include decidual hemorrhage, (e.g., abruption), mechanical factors such as uterine over distension from multiple gestation or polyhydramnios), cervical incompetence (e.g., trauma, cone biopsy) and uterine distortion (e.g., müllerian duct abnormalities, fibroid uterus). In addition, cervical inflammation (e.g., resulting from bacterial vaginosis [BV], trichomonas), maternal inflammation/ fever (e.g., urinary tract infection), hormonal changes (e.g., mediated by maternal or fetal stress), and uteroplacental insufficiency (e.g., hypertension, insulin-dependent diabetes, drug abuse, smoking, alcohol consumption) (2).

Risk factors for preterm birth include demographic characteristics, behavioral factors, and aspects of obstetric history such as previous preterm birth. Demographic factors for preterm labor include nonwhite race, extremes of maternal age $(<17$ y or $>35 \mathrm{y})$, low socioeconomic status, and low pre-pregnancy weight ${ }^{(\mathbf{1})}$.

Among high-risk women with a history of one or more spontaneous preterm births (excluding those with multiple gestation, uterine anomalies, and prior cervical surgeries), $20 \%$ of patients demonstrated a cervical length shorter than $25 \mathrm{~mm}$ by transvaginal ultrasonography at $22-25$ weeks. Among these patients with a short cervix and one previous preterm birth, $37.5 \%$ delivered at less than 35 weeks. In contrast, patients with a cervical length longer than $25 \mathrm{~mm}$ had a preterm rate $(<35 \mathrm{wk})$ of only $10.6 \%$. Cervical length has similarly been demonstrated as the optimal predictor of preterm delivery in low-risk women. In an assessment of low-risk women, short cervical length at $24-28$ weeks was detected in $8.5 \%$ of women ${ }^{(3)}$.

The risk of neonatal mortality and morbidity is low after 34 completed weeks of gestation; although a trial of acute tocolysis may be initiated; aggressive tocolytic therapy is generally not recommended beyond 34 weeks, due to potential maternal complications. Between 24 and 33 weeks' gestation, benefits of tocolytic therapy are generally accepted to outweigh the risk of maternal and/or fetal complications and these agents should be initiated provided no contraindications exist. Although aggressive tocolysis is not typically used beyond 34 weeks' gestation, clinicians are advised not to deliver patients at this gestation without indication because of a higher risk of neonatal morbidity in infants born at 34-36 weeks' gestation compared with deliveries at 37-40 weeks' gestation ${ }^{(4)}$.

Magnesium sulfate is widely used as the primary tocolytic agent. Common maternal side effects include flushing, nausea, headache, drowsiness, and blurred vision. The mother should be monitored for toxic effects, such as respiratory depression or even cardiac arrest that can occur at supratherapeutic levels. In addition, magnesium sulfate readily crosses the placenta and may lead to respiratory and motor depression of the neonate. Several observational studies have reported an association of antenatal treatment with magnesium sulfate for preterm labor or preeclampsia with a decreased risk of cerebral palsy in low birth weight or preterm infants ${ }^{(5)}$.

Nifedipine, a calcium channel blocker, is commonly used to treat high blood pressure and heart disease because of its ability to inhibit contractility in smooth muscle cells by reducing calcium influx into cells. Consequently, nifedipine has emerged as an effective and safe alternative tocolytic agent for the management of preterm labor. Despite its unlabeled status, several randomized studies have shown that the use of nifedipine in comparison with other tocolytic is associated with a more frequent successful prolongation of pregnancy, resulting in significantly fewer admissions of newborns to the neonatal intensive care unit. In addition, it may be associated with a lower incidence of RDS, necrotizing enterocolitis, and intraventricular hemorrhage ${ }^{(6)}$.

\section{Aim of the Work}

The aim of this study is to compare the effect of oral nifedipine, intravenous ritodrine infusion and magnesium sulfate infusion used as tocolytics in cases of preterm labour on Doppler parameters of fetal umbilical and middle cerebral artery and to evaluate their effects on the mother and the fetus in order to choose the safest and the most effective drug.

\section{Patients and Methods}

This study was held in the period from April 2017 to April 2018 on 90 patients admitted from the Obstetric Department in Damanhour Teaching Hospital with preterm labor pains, intact membranes, singleton pregnancy between 28 and 34 weeks gestation. The study was approved by the Ethics Board of Al-Azhar University.

All patients were dated accurately with a gestational age based on the last menstrual period and if available a second trimester ultrasound report was performed before 20 weeks gestation. They were divided into three groups and assigned for the following drugs:

Group A: 30 patients received intravenous ritodrine 
Comparative Study between the Effect of Nifedipine, Ritodrine and Magnesium Sulphate Therapy...

infusion.

Group B: 30 patients received oral nifedipine.

Group C: 30 patients received intravenous magnesium sulphate

Regimens of administration of tocolytics:

Group A: 30 women received ritodrine by intravenous infusion commenced by $50 \mu \mathrm{g} /$ minute (one ampoule $50 \mathrm{mg}$ on $500 \mathrm{ml}$ glucose $5 \%$ at a rate of $10 \mathrm{drops} / \mathrm{min}$, if contractions persisted increase rate by 5 drops every $5 \mathrm{~min}$ till no contractions). Maternal heart rate should not exceed 120 beats/minute. The dose was increased by $50 \mu \mathrm{g}$ every 20 minutes intervals until contractions stopped or unacceptable side effects occurred.

The lowest effective dose was maintained for 24 hours after cessation of contractions. The maximum recommended dose is $350 \mu \mathrm{g} /$ minute.

Group B: 30 women received nifedipine orally. Nifedipine therapy will be initiated with a 10 mg capsule, if uterine contractions continued to persist after 15 minutes a second $10 \mathrm{mg}$ dose will be given and it will be administered twice more if necessary up to a maximum dose of $40 \mathrm{mg}$ nifedipine in the first hour of loading therapy. A maintenance dose of $80-120 \mathrm{mg}$ nifedipine/ $24 \mathrm{hr}$.

Group C: 30 women received magnesium sulfate infusion of the primary dose of $4 \mathrm{~g}$ followed by continuous infusion of $1 \mathrm{~g} / \mathrm{hr}$ as maintenance dose.

Inclusion criteria:

1-Singleton pregnancy between 28 and 34 weeks with intact membranes.

2-Labor is diagnosed when painful regular uterine contractions (3-5 contractions in 10 minutes for more than one hour) associated with cervical changes.

Exclusion criteria:

1- Multiple pregnancy.

2- Evident intrauterine infection.

3- Congenital anomalies in the fetus, fetal growth restriction, fetal distress, fetal death.

4- Clinical diagnosis of abruptio placentae, placenta previa with life threatening bleeding.

5- Maternal medical problems as severe preeclampsia, cardiovascular disease, hyperthyroidism, any maternal contraindication for the use of tocolytic drugs.

6- Cervix dilated more than $4 \mathrm{~cm}$.

All patients were subjected to:

1- Verbal consent.

2- History taking: Personal history, Present history, Obstetric history, Menstrual history, Past history and Family history.

3- General examination: With special attention to blood pressure, pulse and temperature every 20 minutes until a stable dose was achieved and every 4 hours thereafter. Blood pressure for all the patients was above $80 / 50 \mathrm{mmHg}$ before the commencement of treatment. Mean arterial pressure (MAP) was calculated according the equation: MAP $=$ Diastolic BP + 1/3 (Systolic BP - Diastolic BP)

4- Abdominal examination: To measure the fundal level, palpate the uterine contractions and monitoring of the fetal heart rate.

5- Pelvic examination: To assess the state of membranes and exclude their rupture through examination with a sterile Cusco speculum to exclude vaginal bleeding and assess the state of the cervix and measure the bishop score.

6- Sonographic assessment: To estimate the gestational age, amount of liquor and to exclude placenta previa, placental abruption and major fetal congenital anomalies. Several ultrasound parameters were used to estimate gestational age including biparietal diameter (BPD), head circumference (HC), and femur length (FL).

7- Electronic monitoring of uterine contractions and fetal heart rate until the uterine contractions disappeared: Afterwards, fetal heart rate and uterine contractions were monitored for 1 hour every 12 hours during hospital admission.

Uterine contractions were measured by placing the transducer on the abdomen close to the fundus. The transducer was held against the abdominal wall, and as the uterus contracted, a measurable electric signal that indicated the relative intensity of the contraction was recorded.

Fetal heart rate was recorded by another transducer placed at the point of maximum intensity of the fetal heart sound, which was related to the fetal presentation and position.

8-Administration of tocolytic agent in the form of intravenous magnesium sulfate, intravenous ritodrine or oral nifedipine: Initial response was defined if uterine contractions were suppressed within 2 hours of tocolytic treatment. Treatment continued until contractions stopped for 24 hours, maximum doses attained without response; unacceptable side effects occurred or labor proceeded. Successful treatment was defined as cessation of contractions observed for 24 hours and no further cervical changes. Tocolytic failure was defined as the persistence of symptomatic uterine contractions despite maximal attainable doses of therapy, rupture of previously intact membranes, or occurrence of severe side effects necessitating discontinuation of therapy. Patients with successful treatment were put under observation for another 24 hours without additional treatment then discharged on no maintenance therapy. All patients received 12 $\mathrm{mg}$ intramuscular betamethasone with another dose 24 hour later to promote fetal lung maturation.

9- Doppler waveforms of umbilical and middle cerebral arteries were measured from 30 pregnant women and fetuses prior to and at 24 hour after the 
first dose of tocolytic drug therapy (nifedipine, ritodrine and magnesium sulfate). For preterm labor, Doppler examinations were performed by the same investigator making all the measurements (for each patient) during periods without contractions, with the mother lying in a left recumbent position. All examinations were performed in the absence of fetal movement or breathing.

\section{The primary outcome:}

Doppler parameter (PI of umbilical artery and middle cerebral artery and cerebroplacental ratio) before administration of tocolytic agents and 24 hour after administration.

\section{Secondary outcome parameters:}

Efficacy of the three tocolytic agents in the management of preterm labor (cessation of contractions) and maternal side effects of the three tocolytic agents.

\section{Statistics:}

Data were statistically described in terms of range, median, mean \pm standard deviation $( \pm \mathrm{SD})$, frequencies, number of cases and percentages when appropriate. Comparisons of numerical variables between the study groups will be done using one way analysis of variance (ANOVA) test with posthoc multiple 2-group comparisons. Within group comparisons between pre and post treatment values were done using paired t test. For comparing categorical data, Chi square $\left(\chi^{2}\right)$ test was performed. Exact test was used instead when the expected frequency is less than 5 . A probability value ( $p$ value) less than 0.05 was considered statistically significant. All statistical calculations were done using computer programs Microsoft Excel 2003 (Microsoft Corporation, USA) and SPSS (Statistical Package for the Social Science; SPPS Inc., Chicago, IL, USA) version 15 for Microsoft windows.

\section{Results}

Table (1): Comparison of the three study groups according to the maternal age

\begin{tabular}{|c|c|c|c|c|}
\hline & Nifedipine & Magnesium sulfate & Ritodrine & Total \\
\hline \hline Number of cases & 30 & 30 & 30 & 90 \\
\hline \hline Range & $16-39$ & $17-36$ & $19-42$ & $16-42$ \\
\hline \hline Mean & 25.67 & 25.97 & 27.97 & 25.87 \\
\hline \hline $\begin{array}{l}\text { Standard } \\
\text { deviation }\end{array}$ & 5.268 & 4.115 & 6.278 & 5.236 \\
\hline \hline P value & \multicolumn{2}{|c|}{0.968} & \\
\hline
\end{tabular}

When comparing the three study groups, it was found that the mean maternal age for the nifedipine group was $25.67 \pm 5.268$ years old, for the magnesium sulfate group $25.97 \pm 4.115$ years old, and for the ritodrine group it was $27.97 \pm 6.278$ years. The p-value for the three groups $=0.968$ which is statistically nonsignificant.

Table (2): Comparison of the three study groups according to previous preterm labor

\begin{tabular}{|c||c|c||c||c||}
\hline \hline & Nifedipine & $\begin{array}{c}\text { Magnesium } \\
\text { Sulfate }\end{array}$ & Ritodrine & Total \\
\hline $\begin{array}{c}\text { Number of } \\
\text { cases }\end{array}$ & 30 & 30 & 30 & 90 \\
\hline \hline Range & $0-3$ & $0-2$ & $0-2$ & $0-3$ \\
\hline \hline Mean & 0.63 & 0.70 & 0.50 & 0.61 \\
\hline \hline $\begin{array}{c}\text { Standard } \\
\text { deviation }\end{array}$ & 0.765 & 0.750 & 0.630 & 0.714 \\
\hline \hline P value & \multicolumn{3}{|c|}{0.549} \\
\hline
\end{tabular}

When comparing the three study groups, it was found that the mean number of previous preterm labors for the nifedipine group was $0.63 \pm 0.765$, for the magnesium sulfate group $0.7 \pm 0.750$ and for the ritodrine group it was $0.5 \pm 0.630$. The $p$-value for the three groups $=0.549$ which is statistically non-significant.

Table (3): Comparison of the three study groups according to gestational age on admission 
Comparative Study between the Effect of Nifedipine, Ritodrine and Magnesium Sulphate Therapy...

\begin{tabular}{|c||c||c||c||c||}
\hline & Nifedipine & $\begin{array}{c}\text { Magnesium } \\
\text { sulfate }\end{array}$ & Ritodrine & Total \\
\hline \hline $\begin{array}{c}\text { Number of } \\
\text { cases }\end{array}$ & 30 & 30 & 30 & 90 \\
\hline Range & $29-34$ & $29-34$ & $28-34$ & $28-34$ \\
\hline \hline Mean & 31.03 & 31.13 & 30.97 & 31.04 \\
\hline $\begin{array}{c}\text { Standard } \\
\text { deviation }\end{array}$ & 1.474 & 1.592 & 1.629 & 1.550 \\
\hline \hline P value & \multicolumn{2}{|c|}{0.918} \\
\hline
\end{tabular}

When comparing the three study groups, it was found that the mean gestational age in weeks on admission for the nifedipine group was $31.03 \pm 1.474$, for the magnesium sulfate group $31.13 \pm 1.592$ and for the ritodrinegroup it was $30.97 \pm 1.629$. The $\mathrm{p}$-value for the three groups $=0.918$ which is statistically nonsignificant.

Table (4): Comparison of the three study groups as a change in maternal heart rate before and after treatment

\begin{tabular}{|c|c|c|}
\hline \multicolumn{3}{|c|}{ Nifedipine } \\
\hline & Before treatment & After treatment \\
\hline Number of cases & 30 & 30 \\
\hline Range & $74-99$ & $82-102$ \\
\hline Mean & 86.93 & 90.83 \\
\hline Standard deviation & 5.747 & 4.893 \\
\hline $\begin{array}{l}\text { P value (before to after } \\
\text { treatment) }\end{array}$ & \multicolumn{2}{|c|}{0.061} \\
\hline \multicolumn{3}{|c|}{ Magnesium Sulfate } \\
\hline & Before treatment & After treatment \\
\hline Number of cases & 30 & 30 \\
\hline Range & $75-95$ & $76-103$ \\
\hline Mean & 84.87 & 89.37 \\
\hline Standard deviation & 5.090 & 6.542 \\
\hline $\begin{array}{c}\text { P value (before to after } \\
\text { treatment) }\end{array}$ & \multicolumn{2}{|c|}{0.058} \\
\hline \multicolumn{3}{|c|}{ Ritodrine } \\
\hline & Before treatment & After treatment \\
\hline Number of cases & 30 & 30 \\
\hline Range & $65-90$ & $75-105$ \\
\hline Mean & 76.23 & 90.7 \\
\hline Standard deviation & 6.383 & 8.276 \\
\hline $\begin{array}{c}\text { P value (before to after } \\
\text { treatment) }\end{array}$ & \multicolumn{2}{|c|}{0.001} \\
\hline
\end{tabular}

All of the three drugs caused an increase in the maternal heart rate after their administration however it reached a statistically significant value only in the ritodrine group. 
Hosam Eldin Kamel et al.

Table (5): Comparison of the three study groups as a change in fetal heart rate before and after treatment

\begin{tabular}{|c|c|c|}
\hline \multicolumn{3}{|c|}{ Nifedipine } \\
\hline & Before treatment & After treatment \\
\hline Number of cases & 30 & 30 \\
\hline Range & $122-164$ & $126-166$ \\
\hline Mean & 142.63 & 146.97 \\
\hline Standard deviation & 9.704 & 10.997 \\
\hline $\begin{array}{c}\text { P value (before to after } \\
\text { treatment) }\end{array}$ & \multicolumn{2}{|c|}{0.061} \\
\hline \multicolumn{3}{|c|}{ Magnesium sulfate } \\
\hline & Before treatment & After treatment \\
\hline Number of cases & 30 & 30 \\
\hline Range & $122-158$ & $124-160$ \\
\hline Mean & 140.13 & 142.23 \\
\hline Standard deviation & 10.438 & 10.054 \\
\hline $\begin{array}{c}\text { P value (before to after } \\
\text { treatment) }\end{array}$ & \multicolumn{2}{|c|}{0.080} \\
\hline \multicolumn{3}{|c|}{ Ritodrine } \\
\hline & Before treatment & After treatment \\
\hline Number of cases & 30 & 30 \\
\hline Range & $118-154$ & $130-168$ \\
\hline Mean & 135.77 & 153.1 \\
\hline Standard deviation & 12.492 & 11.241 \\
\hline $\begin{array}{c}\text { P value (before to after } \\
\text { treatment) }\end{array}$ & \multicolumn{2}{|c|}{0.001} \\
\hline
\end{tabular}

All of the of the three drugs caused an increase in the fetal heart rate after their administration however it reached a statistically significant value only in the ritodrine group.

Table (6): Maternal complications

\begin{tabular}{|c|c|c|c|c|c|}
\hline & Nifedipine & $\begin{array}{c}\text { Magnesium } \\
\text { sulfate }\end{array}$ & Ritodrine & Total & $\begin{array}{c}\mathbf{P} \\
\text { value }\end{array}$ \\
\hline $\begin{array}{l}\text { Tachycardia, } \\
\text { palpitation }\end{array}$ & $\begin{array}{c}4 \\
(13.3 \%) \\
\end{array}$ & $\begin{array}{c}9 \\
(30 \%)\end{array}$ & $\begin{array}{c}25 \\
(83.3 \%) \\
\end{array}$ & $\begin{array}{c}38 \\
(42.2 \%) \\
\end{array}$ & 0.001 \\
\hline Dyspnea & $\begin{array}{c}0 \\
(0 \%)\end{array}$ & $\begin{array}{c}0 \\
(0 \%)\end{array}$ & $\begin{array}{c}4 \\
(13.3 \%)\end{array}$ & $\begin{array}{c}4 \\
(4.4 \%)\end{array}$ & 0.015 \\
\hline
\end{tabular}

Maternal tachycardia, palpitation and dyspnea were more common in the ritodrine group with p-value $=0.000,0.015$ respectively (Statistically significant).

Table (7): Comparison of the three study groups regarding cessation of contractions after treatment

\begin{tabular}{|c|c|c|c|c|c|}
\hline & Nifedipine & $\begin{array}{c}\text { Magnesium } \\
\text { sulfate }\end{array}$ & Ritodrine & Total & $P$ value \\
\hline $\begin{array}{l}\text { Cessation of } \\
\text { contractions }\end{array}$ & $\begin{array}{c}24 \\
(80 \%)\end{array}$ & $\begin{array}{c}21 \\
(70 \%)\end{array}$ & $\begin{array}{c}18 \\
(60 \%)\end{array}$ & $\begin{array}{c}63 \\
(70 \%)\end{array}$ & 0.24 \\
\hline
\end{tabular}

All of the of the three drugs caused cessation of uterine contractions after their administration which was more in the nifedipine group. 
Comparative Study between the Effect of Nifedipine, Ritodrine and Magnesium Sulphate Therapy...

Table (8): Comparison of the three study groups as regard a change in fetal umbilical artery PI before and after treatment

\begin{tabular}{|c|c|c|}
\hline \multicolumn{3}{|c|}{ Nifedipine } \\
\hline & Before treatment & After treatment \\
\hline Number of cases & 30 & 30 \\
\hline Range & $0.9-1.3$ & $0.9-1.3$ \\
\hline Mean & 1.131 & 1.128 \\
\hline Standard deviation & 0.099 & 0.098 \\
\hline $\begin{array}{c}P \text { value (before to after } \\
\text { treatment) }\end{array}$ & \multicolumn{2}{|c|}{0.281} \\
\hline \multicolumn{3}{|c|}{ Magnesium sulfate } \\
\hline & Before treatment & After treatment \\
\hline Number of cases & 30 & 30 \\
\hline Range & $0.8-1.4$ & $0.8-1.4$ \\
\hline Mean & 1.03 & 1.07 \\
\hline Standard deviation & 0.151 & 0.127 \\
\hline $\begin{array}{c}P \text { value (before to after } \\
\text { treatment) }\end{array}$ & \multicolumn{2}{|c|}{0.016} \\
\hline \multicolumn{3}{|c|}{ Ritodrine } \\
\hline & Before treatment & After treatment \\
\hline Number of cases & 30 & 30 \\
\hline Range & $0.9-1.3$ & $0.9-1.3$ \\
\hline Mean & 1.117 & 1.117 \\
\hline Standard deviation & 0.125 & 0.126 \\
\hline $\begin{array}{c}\text { P value (before to after } \\
\text { treatment) }\end{array}$ & \multicolumn{2}{|c|}{0.161} \\
\hline
\end{tabular}

Comparison of the three groups revealed increase in umbilical artery PI after treatment in the magnesium sulfate group only which was statistically significant $(\mathrm{P}$ value $=0.016)$.

Table (9): Comparison of the three study groups as regard change in fetal middle cerebral artery PI before and after treatment

\begin{tabular}{|c|c|c|}
\hline \multicolumn{3}{|c|}{ Nifedipine } \\
\hline & Before treatment & After treatment \\
\hline Number of cases & 30 & 30 \\
\hline Range & $1.16-1.5$ & $1.15-1.5$ \\
\hline Mean & 1.3 & 1.29 \\
\hline Standard deviation & 0.082 & 0.081 \\
\hline $\begin{array}{c}\text { P value (before to after } \\
\text { treatment) }\end{array}$ & \multicolumn{2}{|c|}{0.027} \\
\hline \multicolumn{3}{|c|}{ Magnesium sulfate } \\
\hline & Before treatment & After treatment \\
\hline Number of cases & 30 & 30 \\
\hline Range & $1.2-1.7$ & $1.3-1.8$ \\
\hline Mean & 1.34 & 1.56 \\
\hline Standard deviation & 0.143 & 0.135 \\
\hline $\begin{array}{c}\text { P value (before to after } \\
\text { treatment) }\end{array}$ & \multicolumn{2}{|c|}{0.000} \\
\hline \multicolumn{3}{|c|}{ Ritodrine } \\
\hline & Before treatment & After treatment \\
\hline Number of cases & 30 & 30 \\
\hline Range & $1.1-1.6$ & $1.1-1.6$ \\
\hline Mean & 1.37 & 1.371 \\
\hline Standard deviation & 0.121 & 0.122 \\
\hline $\begin{array}{c}\text { P value (before to after } \\
\text { treatment) }\end{array}$ & \multicolumn{2}{|c|}{0.26} \\
\hline
\end{tabular}


Comparison of the groups revealed statistically significant increase in middle cerebral artery PI after treatment in magnesium sulfate group with a $\mathrm{P}$ value 0.000 and showed statistically significant decrease in nifedipine group with a $\mathrm{P}$ value 0.027 . However, the decrease was within clinically acceptable levels.

Table (10): Comparison of the three study groups as regard a change in cerebroplacental ratio before and after treatment.

\begin{tabular}{|c|c|c|}
\hline \multicolumn{3}{|c|}{ Nifedipine } \\
\hline & Before treatment & After treatment \\
\hline Number of cases & 30 & 30 \\
\hline Range & $1.04-1.37$. & $1.04-1.37$ \\
\hline Mean & 1.15 & 1.148 \\
\hline Standard deviation & 0.96 & 0.091 \\
\hline $\begin{array}{c}\text { P value (before to after } \\
\text { treatment) }\end{array}$ & \multicolumn{2}{|c|}{0.37} \\
\hline \multicolumn{3}{|c|}{ Magnesium sulfate } \\
\hline & Before treatment & After treatment \\
\hline Number of cases & 30 & 30 \\
\hline Range & $1.08-1.55$ & $1.25-1.77$ \\
\hline Mean & 1.32 & 1.48 \\
\hline Standard deviation & 0.11 & 0.13 \\
\hline $\begin{array}{c}\text { P value (before to after } \\
\text { treatment) }\end{array}$ & \multicolumn{2}{|c|}{0.000} \\
\hline \multicolumn{3}{|c|}{ Ritodrine } \\
\hline & Before treatment & After treatment \\
\hline Number of cases & 30 & 30 \\
\hline Range & $1.08-1.44$ & $1.08-1.44$ \\
\hline Mean & 1.23 & 1.22 \\
\hline Standard deviation & 0.079 & 0.081 \\
\hline $\begin{array}{c}\text { P value (before to after } \\
\text { treatment) }\end{array}$ & \multicolumn{2}{|c|}{0.5} \\
\hline
\end{tabular}

Comparison of the three groups revealed significant increase in cerebroplacental ratio after treatment in the magnesium sulfate group with $\mathrm{P}$ value $=0.000$ which is statistically significant.

\section{Discussion}

Spontaneous preterm labor (SPTL) and preterm birth (PTB) is defined as birth before 37 completed weeks and is the single most important cause of perinatal mortality and morbidity in highincome countries ${ }^{(7)}$.

All the pharmacological agents used to inhibit preterm uterine contractions act by affecting intracellular calcium concentration in the myometrial cells. Some of these agents promote the extrusion of calcium from the cell (beta-adrenergic agents and indomethacin), some displace calcium (magnesium sulphate) and some block the entrance of calcium into the myometrial cells (calcium channel blockers). Indomethacin also acts by inhibiting prostaglandin production ${ }^{(8)}$. Selective beta-mimetic drugs are the most frequently used agents for arresting preterm labor. For this purpose, these drugs have to be given in high doses for several hours and since they act on several organ systems, side effects appear, some of which are potentially dangerous. These hazards, which involve chiefly the cardiovascular and metabolic areas, have been examined in the light of available experience with these drugs ${ }^{(9)}$. Ritodrine is a betasympathomimetic drug that is frequently used for the prevention of preterm birth. One of the most important side effects of ritodrine is pulmonary edema ${ }^{(\mathbf{1 0})}$.

The lower incidence of side effects in comparison with $B$-agonists undoubtedly has been the prime incentive to start the use of calcium channel blockers for tocolysis ${ }^{(11)}$. The side effects also appear to have less impact on maternal wellbeing and are of shorter duration.

Contrary to ritodrine, nifedipine had minimal effects on maternal pulse rate, systolic and diastolic blood pressure, serum potassium concentrations and blood glucose levels ${ }^{(\mathbf{1 2})}$.

The RCOG Green Top Guidelines in 2002 stated that when a tocolytic is required, nifedipine or atosiban (an oxytocin receptor antagonist) should be used as the preferred first line tocolytic agent, in preference to beta- mimetics.

In the present study, which was held on 90 patients divided into three groups, analysis of the characteristics of the studied population showed the following results:

When comparing the mean maternal age it was found to be $25.67 \pm 5.268$ (16-39), $25.97 \pm$ 4.115 (17-36), $27.97 \pm 6.278$ (19-42) years old for 
Comparative Study between the Effect of Nifedipine, Ritodrine and Magnesium Sulphate Therapy...

nifedipine, magnesium sulfate and ritodrine, respectively. When comparing those results the pvalue was found to be 0.968 , which is statistically non-significant.

When comparing the three study groups, it was found that the mean parity for the nifedipine group was $2.23 \pm 1.135(0-5)$, for the magnesium sulfate group $2.13 \pm 0.900(1-4)$ and for the ritodrine group it was $2.27 \pm 0.944$ (1-4). The pvalue for the three groups was 0.865 , which is statistically non-significant.

In addition, when we compared the three study groups, it was found that the mean number of previous preterm labors for the nifedipine group was $0.63 \pm 0.765(0-3)$, for the magnesium sulfate group $0.70 \pm 0.750(0-2)$, and for the ritodrine group it was $0.50 \pm 0.63(0-2)$. The p-value for the three groups was 0.549 , which is statistically nonsignificant.

The bishop score was calculated at admission and the mean of the bishop scores for each study group was calculated. For the Nifedipine group it was $4.70 \pm 2.087$ (2-8), for the Magnesium sulfate group it was $4.70 \pm 2.120$ (2-8) and for the Ritodrine group it was $5.27 \pm 1.837$ (28 ).When comparing the three results, the p-value for the three groups was 0.458 which is statistically non-significant.

The mean gestational age at admission for the women included in the nifedipine group was $31.03 \pm 1.474$ weeks, for the magnesium sulfate group the mean gestational age at admission was $31.13 \pm 1.592$ weeks, and for the ritodrine group it was $30.97 \pm 1.629$ weeks. When comparing the results of the three study groups, the p-value was found to be 0.918 , which is statistically nonsignificant.

The characteristics of the study population included in our study were not much different from the study held by Conde-Agudelo et al. ${ }^{(6)}$ on 80 patients divided into two groups to compare the efficacy of nifedipine and ritodrine in prolonging pregnancy beyond 48 hours, 1 week and 36 weeks. The mean maternal age in this study was $26.2 \pm 6.5$ years for the ritodrine group while it was $26.9 \pm 6.1$ years for the nifedipine group. The mean gestational age on admission was $32.1 \pm 2.1$ weeks for ritodrine group and $32.2 \pm 2.2$ weeks for nifedipine group. While the mean bishop score was $2.9 \pm 1.9$ and $2.7 \pm 1.8$ for the ritodrine and nifedipine groups respectively. However, the parity for both groups ranged from 0-3, which is logically less than that in our study due to the increased parity in the developing countries as Egypt more than that in the developed countries as Ireland where the study was held.
A series of studies were done and showed that nifedipine, magnesium sulfate and ritodrine were effective in the management of preterm labor. Most of the studies were comparing only two drugs with each other. However, in the present study we compared the three drugs in their efficacy, maternal and fetal side effects.

In our study, when we observed the cardiovascular changes that occurred after administration of the three drugs, it showed that all of the three drugs caused an increase in the maternal heart rate after their administration. However, it reached a statistically significant value only in the ritodrine group. In the ritodrine group, the mean maternal heart rate was $76.23 \pm 6.383$ bpm before ritodrine administration and reached $90.70 \pm 8.276 \mathrm{bpm}$ after its administration. The $\mathrm{p}-$ value was 0.000 denoting a statistically significant value. While in the nifedipine group, the mean maternal heart rate was $86.93 \pm 5.747 \mathrm{bpm}$ before treatment and reached $90.83 \pm 4.893 \mathrm{bpm}$ after treatment with p-value 0.061 denoting a statistically non-significant value. In addition, in the magnesium sulfate group the maternal heart rate changed from $84.87 \pm 5.090 \mathrm{bpm}$ to $89.37 \pm$ $6.542 \mathrm{bpm}$ with p-value 0.058 , which is statistically non-significant. There were no statistical difference in the maternal heart rate between the three groups before administration of the drugs (pvalue $=0.172)$. While, after their administration a statistically significant difference was noted between ritodrine group and the other two groups at all-time points of treatment ( $\mathrm{p}$-value $=0.000$ ).

Considering the changes that occurred in the maternal mean blood pressure before and after treatment, all of the three drugs caused statistically significant decrease in the maternal mean blood pressure after their administration. In the three study groups the maternal mean blood pressure changed from $85.63 \pm 5.962,88.03 \pm 4.514,91.01$ $\pm 10.423 \mathrm{~mm} \mathrm{Hg}$ before treatment to $77.03 \pm 5.183$, $86.4 \pm 5.21,84.83 \pm 10.787 \mathrm{~mm} \mathrm{Hg}$ after treatment in the nifedipine, ritodrine, magnesium sulfate groups, respectively . The p-value was 0.000 for the nifedipine and magnesium sulfate group and 0.028 for the ritodrine group, which were all statistically significant.

Fetal heart rate was significantly greater in the ritodrine group at all points during treatment. Fetal heart rate increased from $135.77 \pm 12.492$ bpm to $153.1 \pm 11.241$ bpm (p-value 0.000, statistically significant). While in the nifedipine group, the fetal heart rate increased from $142.63 \pm$ $9.704 \mathrm{bpm}$ to $146.97 \pm 10.997 \mathrm{bpm}$ (p-value 0.061, statistically non-significant). Besides, in the magnesium sulfate group the fetal heart rate slightly changed from $140.13 \pm 10.438 \mathrm{bpm}$ to 
$142.23 \pm 10.054 \mathrm{bpm}$ (p-value 0.08, statistically non-significant).

All significant differences in the maternal and fetal hemodynamic parameters between the three groups resolved after cessation of treatment. This is consistent with the work done by Black $\boldsymbol{e t}$ al. (13) who examined the maternal and fetal cardiovascular effects of GTN compared with ritodrine for acute tocolysis. Sixty women with preterm labor were enrolled in this study. Once randomized, the women received transdermal GTN or intravenous ritodrine according to the guidelines of the RCOG. Measurements of the maternal pulse, blood pressure, and fetal heart rate were recorded for up to 24 hours and compared over the treatment course. The mean maternal heart rate was lower in the GTN group $(p<0.01)$, the mean fetal heart rate was significantly lower during GTN treatment $(p=0.008)$. Ritodrine had a significantly hypotensive effect on mean arterial pressure. Mean arterial pressure was not significantly different over the treatment course with GTN.

In the present study, there was cessation of contractions in the three study groups after administration of the drugs, which was more evident in nifedipine group (80\%). When comparing the presence of contractions among the three groups with each other after treatment; it was found that the difference had no significant value (P value 0.24). This meant that all of the three drugs caused cessation of contractions nearly with the same efficacy.

In our study, when we observed the Doppler changes on fetal umbilical and middle cerebral arteries that occurred after administration of the three drugs, it showed increase in umbilical artery PI after treatment in the magnesium sulfate group only, which was statistically significant $(\mathrm{P}$ value $=0.016)$. In the ritodrine group, the mean umbilical PI was $1.117 \pm 0.125$ before ritodrine administration and reached $1.117 \pm 0.126$ after its administration. The $\mathrm{p}$-value was 0.161 denoting a statistically non-significant value. While in the nifedipine group, the mean umbilical PI was 1.131 \pm 0.099 before treatment and reached $1.128 \pm 0.098$ after treatment with p-value 0.281 denoting a statistically non-significant value.

The study showed statistically significant increase in middle cerebral artery PI after treatment in magnesium sulfate group with a $P$ value 0.000 and showed statistically significant decrease in nifedipine group with a $\mathrm{P}$ value 0.027 and the decrease was within clinically acceptable levels. In the nifedipine group, the mean MCA PI was $1.3 \pm$ 0.082 before nifedipine administration and reached $1.29 \pm 0.081$ after its administration. The p-value was 0.027 denoting a statistically significant value. While in the ritodrine group, the mean MCA PI was $1.37 \pm 0.121$ before treatment and reached $1.371 \pm 0.122$ after treatment with $p$ value 0.26 denoting a statistically non-significant value.

When comparing the cerebroplacental ratio before and after treatment in the three groups; the study showed significant increase in cerebroplacental ratio after treatment in the magnesium sulfate group with $\mathrm{P}$ value $=0.000$ which, was statistically significant. In the nifedipine group the mean cerebroplacental ratio was1.15 \pm 0.96 before nifedipine administration and reached $1.148 \pm 0.091$ after its administration. The p-value was 0.370 denoting a statistically nonsignificant value. While in the ritodrine group, the mean cerebroplacental ratio was $1.23 \pm 0.079$ before treatment and reached $1.22 \pm 0.081$ after treatment with p-value 0.5 denoting a statistically non-significant value.

\section{Conclusion and Recommendations}

The present study showed that there was no overall difference between ritodrine, nifedipine, and magnesium sulfate in their efficacy as tocolytic for preterm labor.

In addition, it showed that the maternal side effects profile was fewer with nifedipine and magnesium sulfate than with ritodrine. This suggests that nifedipine and magnesium sulfate could be used as a safer effective alternative to ritodrine.

In our study, nifedipine therapy was not associated with a significant change in maternal systolic and diastolic blood pressure after $24 \mathrm{~h}$, with minor insignificant effect on maternal heart rate. Fetal heart rate was not affected after therapy. Fetal Doppler study found no clinically significant effect on the pulsatility index (PI) of umbilical and middle cerebral artery. While with magnesium sulfate therapy, there was increase in cerebroplacental ratio $24 \mathrm{hr}$ after treatment, these findings ensure safety of the drugs on the maternal and fetal aspects.

Although the sample size we studied was reasonable, it might be difficult to give clear recommendations upon our results only, and it is proposed that further larger multi-centric studies would be done on this topic to confirm or negate our results.

Also, it is recommended that other tocolytic drugs would be included in further researches especially atosiban, an oxytocin antagonist, which is used as the first line of tocolysis in some other countries, however the experience of using this drug in Egypt is still very limited due to financial and availability issues. 
Comparative Study between the Effect of Nifedipine, Ritodrine and Magnesium Sulphate Therapy...

\section{Reference}

1. ACOG (2001): Practice Bulletin No. 31: Assessment of Risk Factors for Preterm Birth. Obstet Gynecol., 98(4): 709-716

2. Wilcox AJ, Skjærven $R$ and Lie RT (2007): Familial Patterns of Preterm Delivery: Maternal and Fetal Contributions. Am. J. Epidemiol., 28: 915.

3. Durnwald CP, Walker H, Lundy JC et al. (2005): Rates of recurrent preterm birth by obstetrical history and cervical length. Am. J. Obstet. Gynecol., 193 (3 Pt 2): 1170-4.

4. Cheng Y, Kaimal A, Bruckner T et al. (2011): Perinatal morbidity associated with late preterm deliveries 133 compared with deliveries between 37 and 40 weeks of gestation. BJOG., 118 (12): 1446-1454.

5. Conde-Agudelo $A$ and Romero $R$ (2009): Antenatal magnesium sulfate forthe prevention of cerebral palsy in preterm infants less than 34 weeks' gestation: a systematic review and metaanalysis. Am. J. Obstet. Gynecol., 200 (6): 595-609.

6. Conde-Agudelo A, Romero $R$ and Kusanovic JP (2011): Nifedipine in the management of preterm labor: a systematic review and metaanalysis. Am. J. Obstet. Gynecol., 204 (2): 134.

7. Papatsonis D, Flenady V, Cole S et al. (2005): Oxytocin receptor antagonists for inhibiting preterm labour. Cochrane Database Syst. Rev., 3: 15-45.

8. Macones GA, Bader TJ and Asch DA (1998): Optimising maternal-fetal outcomes in preterm labour: a decision analysis. Br. J. Obstet. Gynaecol., 105 (5): 541-50.

9. Ingemarsson I, Arulkumaran $S$ and Kottegoda SR (1985): Complications of beta-mimetic therapy in preterm labour. Aust. N. Z. J. Obstet. Gynaecol., 25 (3): 182-9.

10. Karaman S, Ozcan O, Akercan F et al. (2004): Pulmonary edema after ritodrine therapy during pregnancy and subsequent cesarean section with epidural anesthesia. Clin. Exp. Obstet. Gynecol., 31 (1): 67-9.

11. Murray C, Haverkamp AD, Orleans $M$ et al. (1992): Nifedipine for treatment of preterm labor: a historic perspective study. Am. J. Obstet. Gynecol., 167: 52- 56.

12. Papatsonis DNM, Lok CAR, Bos J et al. (2001): Calcium channel blockers in the management of preterm labor and hypertension in pregnancy. Eur. J. Obstet. Gynecol. Reprod. Biol., 97: 122 -140.

13. Black RS, Lees $C$, Thompson $C$ et al. (1999): Maternal and fetal cardiovascular effects of transdermal glyceryl trinitrate and intravenous ritodrine. Obstet. Gynecol., 94(4):572-6. 